\title{
Non-vascularized fibular graft reconstruction after resection of giant aneurysmal bone cyst (ABC)
}

\author{
Freih Odeh Abuhassan · Akram Shannak
}

Received: 4 August 2009/Accepted: 3 August 2010/Published online: 2 September 2010

(C) The Author(s) 2010. This article is published with open access at Springerlink.com

\begin{abstract}
The aim of this study was to present the results of non-vascularized fibular graft for reconstruction of bone defects after en block resection of giant aneurysmal bone cyst (ABC) of the extremities. Between 1998 and 2006, three patients, aged 6,8 and 23 years, with giant aneurysmal bone cysts were treated. The cysts were located in the humerus, proximal femur and metatarsal. All patients were given en bloc resection of the cyst followed by nonvascularized fibular bone graft, with the graft length ranging from 6 to $18 \mathrm{~cm}$. All patients needed supplementary fixation with a single Kirschner wire or plate and screws. At the final follow-up, bony union was achieved in each case, and there was no recurrence, limitation of range of motion or disability. In addition, complete regeneration of the fibula at the donor site was seen in the two children. We propose a criterion for giant $\mathrm{ABC}$, when the transverse diameter of the cyst is up to three times or more of the transverse diameter of the nearby bone, it is then called a giant ABC. Non-vascularized fibular graft is an optimal and valuable method for the reconstruction of bone defects after resection of giant $\mathrm{ABC}$ in the extremities.
\end{abstract}

Keywords Resection - Giant ABC - Bone tumor .

Non-vascularized fibular graft

\section{Introduction}

$\mathrm{ABC}$ is a benign, expansile, non-neoplastic lesion of the bone, characterized by channels of blood and spaces

F. O. Abuhassan $(\bowtie) \cdot$ A. Shannak

The Department of Orthopaedic Surgery, Jordan University,

P.O. Box 73, Jubaiha, Amman 11941, Jordan

e-mail: freih@ju.edu.jo separated by fibrous septa [1]. Although it is a benign lesion, malignant transformation has been reported [2]. Seventy-five percent of the lesions occur in the first 2 decades of life, and almost $95 \%$ occur in the first 3 decades [3]. It has been shown that at least a subset of ABCs has a specific cytogenetic aberration, most commonly a translocation [4]. It was suggested that $\mathrm{ABC}$ corresponds to a hemodynamic disturbance because of primary or secondary venous malformation of bones [5]. Giant $A B C$ is an uncommon pathological lesion and can be challenging because of the destructive effect of the cyst on the bones and the pressure on the nearby structures, especially on weight-bearing bones.

En bloc resection of the diseased segment is a useful surgical technique in the treatment of benign and malignant bone lesions. The fibula is a strong, long, tubular bone that can be used as a non-vascularized bone graft for restoration of mechanical continuity and efficiency of the limb after bone defects resulting from tumor resection [6-8]. The purpose of this article is to evaluate the clinical and radiological results of the resection and reconstruction of giant ABCs using non-vascularized fibular bone graft.

\section{Patients and methods}

Between 1998 and 2006, three patients with florid manifestations of giant $\mathrm{ABC}$ of the extremities were treated with en bloc resection and reconstruction by non-vascularized strut fibular grafts. There were two children aged 6 and 8 years old and one 23-year-old adult; all were males. The cysts were present in the upper third of the humerus, the proximal part of the femur and the metatarsal diaphysis (Table 1). All patients had painful swelling of 6-14 months' duration. All patients were followed up regularly for 
Table 1 Demographic and clinical data of patients

\begin{tabular}{|c|c|c|c|c|c|c|c|c|}
\hline $\begin{array}{l}\text { Case } \\
\text { no. }\end{array}$ & $\begin{array}{l}\text { Age/ } \\
\text { sex }\end{array}$ & Site & $\begin{array}{l}\text { Size/ } \\
\mathrm{cm}\end{array}$ & $\begin{array}{l}\text { TDC/ } \\
\text { TDB }\end{array}$ & Type of surgical procedure & $\begin{array}{l}\text { Graft } \\
\text { length }(\mathrm{cm})\end{array}$ & Complications & $\begin{array}{l}\text { Follow-up } \\
\text { (years) }\end{array}$ \\
\hline 1 & $8 / \mathrm{M}$ & 3rd Metatarsal & $5 \times 6$ & $5 / 0.7$ & $\begin{array}{l}\text { 1st stage: Resection, graft harvesting, } \\
\text { insertion of the strut graft and fixation } \\
\text { by Kirschner wire. } 2 \text { nd stage: removal } \\
\text { of the Kirschner wire }\end{array}$ & 6 & - & 4 \\
\hline 2 & 23/M & $\begin{array}{l}\text { Proximal third } \\
\text { humerus }\end{array}$ & $9 \times 10$ & $9 / 3$ & $\begin{array}{l}\text { 1st stage: Open biopsy. } 2 n d \text { stage: } \\
\text { Resection, graft harvesting, insertion of } \\
\text { the strut graft, fixation by } \\
\text { intramedullary Kirschner wire and } \\
\text { circlage wire distally. } 3 r d \text { stage: } \\
\text { Autogenous cancellous bone graft, open } \\
\text { reduction and internal fixation by plate } \\
\text { and screws for non-union. } 4 \text { th stage: } \\
\text { Removal of the plate and screws }\end{array}$ & 18 & Non-union & 8 \\
\hline 3 & $6 / \mathrm{M}$ & Proximal femur & $8 \times 8$ & $8 / 1.5$ & $\begin{array}{l}\text { 1st stage: Open biopsy. } 2 \text { nd stage: } \\
\text { Resection, graft harvesting, insertion of } \\
\text { the dual strut graft. } 3 r d \text { stage: Open } \\
\text { reduction and internal fixation by plate } \\
\text { and screws for delayed union. } 4 \text { th stage: } \\
\text { removal of the plate and screws }\end{array}$ & $10 \times 2$ & Delayed union & 3 \\
\hline
\end{tabular}

$T D C$ transverse diameter of the cyst, $T D B$ transverse diameter of the nearby normal bone

3-8 years (mean 5 years). Imaging studies included conventional radiographs and magnetic resonance imaging (MRI). The length of the required fibula for bridging the bone defect was estimated from the MR scans. The strut fibular graft was harvested after resection of the cyst by a lateral skin incision over the middle of the ipsilateral fibula. After that, exposure of the middle of the fibula was performed, and it was dissected sub-periosteally. Care was taken that more than $5 \mathrm{~cm}$ of the proximal and distal fibula was preserved to ensure stability of the knee and ankle. The periosteum was closed in children to facilitate fibular regeneration, and the wound was closed in layers without drainage and then dressed.

\section{Case 1}

An 8-year-old male child presented with painful swelling in the dorsum of the right foot of 6 months' duration. Conventional plain radiographs of the foot showed fusiform dilation and ballooning with a radiolucent area of the metatarsal diaphysis with a very thin outline, causing pressure on the surrounding metatarsal bones. MRI revealed an expansile lobulated bone lesion with multiple septations in the diaphysis of the affected bone (Fig. 1). The lesion was hypointense on $\mathrm{T} 1$ - and hyperintense on T2-weighted images, and the cortices were disrupted. The surgical plan was en bloc excision of the lesion with incorporation of an autogenous interpositional non-vascularized fibular graft. In the operation, a dorsolinear incision was placed over the cystic lesion. The incision passed through layers to the level of the cyst, exposing the full length of the affected bone, which revealed fusiform swelling, as anticipated from plain radiographic and MRI findings. Frozen section indicated the benign nature of the lesion. The thin-walled tumor was resected en bloc with a microsagittal saw. The defect was replaced by a $6-\mathrm{cm}$ segment from the ipsilateral fibula and fixed by Kirschner wire across the osteotomy sites. Postoperatively, the patient used a below-the-knee, non-weight-bearing cast for 6 weeks, then gradually weight bearing was tolerated for another 6 weeks. After 12 weeks, the Kirschner wire was removed, and the patient was allowed a gradual range of joint movement. Radiological follow-up every 3 months in the 1st year then yearly showed complete union with complete graft incorporation and consolidation. There was no evidence of recurrence, as determined radiologically. Moreover, the function of the limb was full, without any disability. Two cases of lesions of the proximal third of the humerus and proximal metaphyseal part of the femur were considered highly aggressive with no defined periosteal shell or bone limits.

\section{Case 2}

A 23-year-old male patient presented with pathological humeral fracture to another hospital. He had open biopsy followed by local curretage and a fibular strut graft without internal fixation. After 14 months, the patient presented to our hospital with painful swelling in the left arm. The patient underwent complete investigations to exclude malignant tumor. Plain radiography showed an osteolytic "blow-out" lobulated lesion outlined by a paper-thin shell 

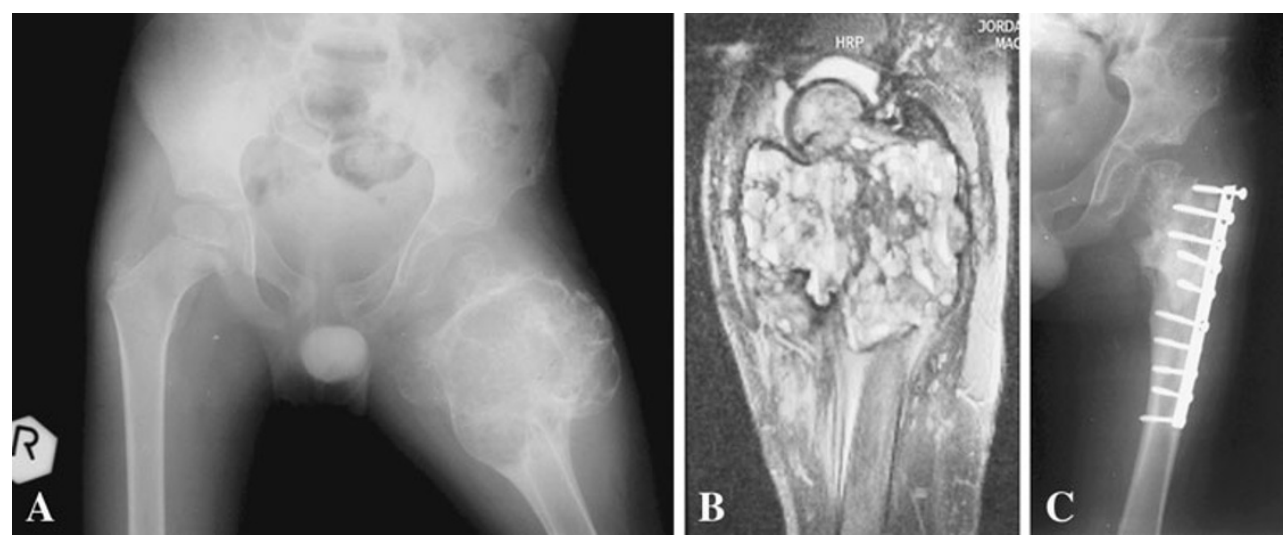

Fig. 1 Case 1: An 8-year-old male child presented with painful swelling in the dorsum of the right foot. a Anterior posterior ( $A P$ ) plain radiograph of the right foot showing an expansive cystic lesion replacing the entire third metatarsal, except for the proximal and distal epiphyses. Diffuse endosteal thinning without a fracture, leaving the cortex as a thin shell with "a balloon" appearance, caused a pressure effect on the nearby metatarsals. b Transverse T2 MRI views of the right foot showing fluid level and hemorrhage

of cortices. Magnetic resonance image (MRI) demonstrated the presence of a $9.0 \times 10.0-\mathrm{cm}$ large cystic expansile lesion in the proximal third of the humerus (Fig. 2). Open biopsy confirmed the benign nature of the aneurysmal bone cyst. Two weeks later, the patient had a wide local resection with a $1.5-\mathrm{cm}$ safety margin as a precaution because of the aggressive nature of the lesion. The defect was bridged by a strut fibular graft that was introduced proximally through a tunnel that was made in the remaining part of the proximal humerus and passed distally through a slit that was made in the remaining distal humerus. Intramedullary, a 3-mm Kirschner wire was introduced through the graft proximally and distally. A cerclage wire was used to hold the fibular graft in the distal part of the humerus. After 18 months, the patient had open reduction and internal fixation with the addition of cancellous iliac crest bone graft for non-union of the distal part of the fibula with the humerus. Careful follow-up showed complete consolidation of the bone, and the patient had a full range of shoulder movement. The plate and screws were removed after 4 years. At 8 years there were hypertrophy and remodeling of the fibular graft.

\section{Case 3}

A 6-year-old male child presented with painful limping on the left side of 12 months' duration. Physical examination demonstrated diffuse swelling in the left hip region with marked tenderness and limitation of the hip range of movement. Plain radiography of the pelvis and hips showed an osteolytic "blow-out" lobulated lesion outlined inside the cyst. $\mathbf{c}$ Sagittal T2 MRI views of the right foot showing a multilobular pattern and hemorrhage inside the cyst. d AP plain radiograph of the right foot 2 weeks postoperatively showing the fibular graft in situ fixed by Kirshner wire. e AP plain radiograph of the right foot 4 years after surgery showing healing, consolidation, remodeling and preserved length of the metatarsal bone. $f$ Photograph of the right foot at the final follow-up showing the surgical scar and alignment of the toes

by a paper-thin shell of cortex over the proximal part of the femur bone. MRI demonstrated the presence of an $8.0 \times 8.0-\mathrm{cm}$ multilocular bone cyst involving the neck and proximal part of the femur (Fig. 3). Well-demarcated multiple fluid levels and internal hemorrhage were also noted. After the diagnosis of ABC was ensured by open biopsy, resection of the tumor through peeling the cyst from the outer periosteum was done without damaging the neurovascular bundles or the surrounding attached tendons. The remaining defect in the proximal femur was bridged by two struts of fibular graft (each $10 \mathrm{~cm}$ in length) harvested subperiosteally from the middle two thirds of the ipsilateral fibula to allow for future regeneration of the fibula. The remaining periosteal sheath of the cyst was closed over the fibular graft, without using internal fixation. Postoperatively, the patient was kept in hip spica for 2 months, then mobilized on crutches for another 4 months. The patient needed fixation of the graft by plate and screws after he had delayed union 4 months after the initial operation as manifested by angulations of the distal part of the graft with the femur. Postoperatively, the patient used crutches with no weight bearing for another 3 months.

Removal of the plate and screws took place after 2 years when full incorporation of the graft was achieved proximally and distally. Grossly, all resected specimens were cystic, with several hollow spaces of varying sizes that were filled up with blood clots. Microscopic examination revealed many septae-forming blood-filled channels. Multinucleated giant cells, osteoid and woven bones were apparent in the septae. No malignant cells were found. 

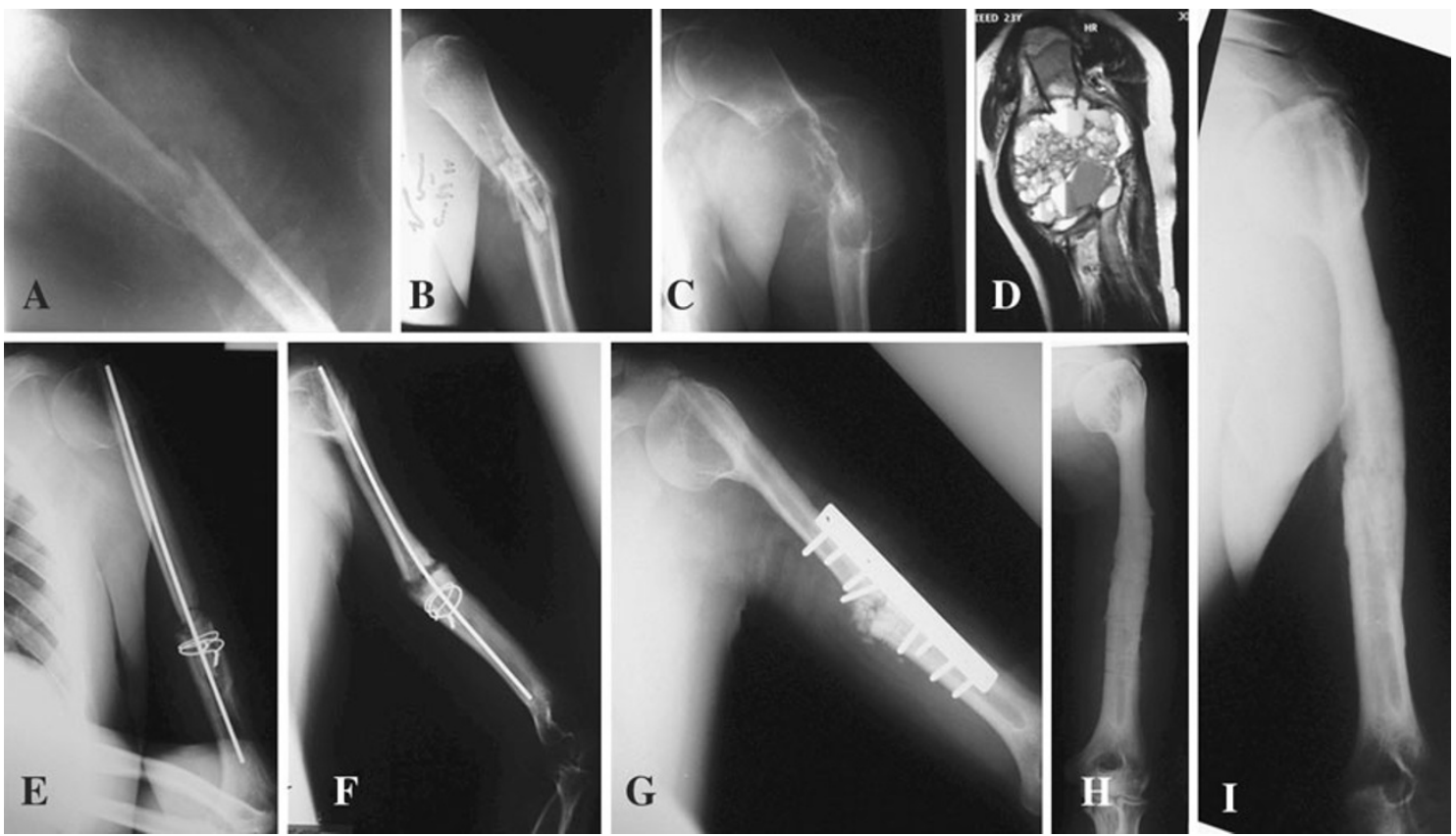

Fig. 2 Case 2: A 23-year-old male patient was diagnosed with $\mathrm{ABC}$ of the humerus. a Anterior posterior $(A P)$ plain radiograph of the left humerus showing pathological fracture of the shaft of the humerus. b AP plain radiograph of the left humerus showing the pieces of the fibular graft at the site of the fracture. c AP plain radiograph of the left humerus showing a large expansile cystic lesion causing total destruction of the bone with ballooning effect. d Coronal T2 MRI views of the left humerus showing multiple fluid levels with hemorrhage inside the cyst. e AP plain radiograph of the left humerus in the immediate postoperative period showing the graft in situ fixed proximally and distally. f AP plain radiograph of the left humerus after 18 months showing healing in the proximal part of the graft and non-union at the distal part. $\mathrm{g}$ AP plain radiograph of the left humerus after open reduction and internal fixation $(O R I F)$ with addition of bone graft. $\mathbf{h}$ AP plain radiograph of the left humerus after removal of metal showing incorporation of the graft proximally and distally. i AP plain radiograph of the left humerus 8 years postoperatively showing good consolidation, hypertrophy and remodeling of the graft

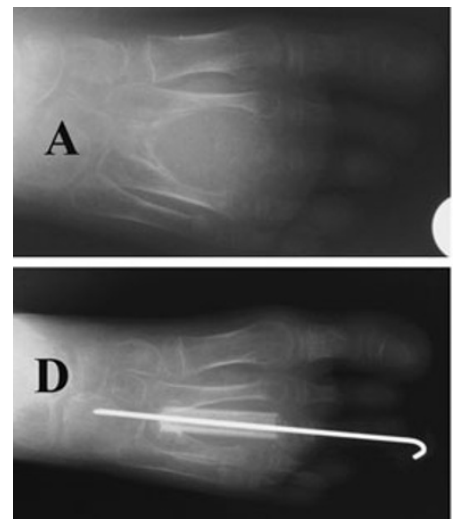

Fig. 3 Case 3: A 6-year-old male child was diagnosed with $\mathrm{ABC}$ of the proximal femur. a Anterior posterior plain radiograph of the pelvis and hips showing an expansile multilocular lytic lesion of the proximal left femur, causing significant destruction with loss of bone architecture. b Coronal T2-weighted MR image shows the bright

\section{Discussion}

We could not find the term "giant aneurysmal bone cyst" in the literature. $\mathrm{ABC}$ can present early before reaching giant size, which facilitates early diagnosis and treatment. It is well known that $\mathrm{ABC}$ is classified as an aggressive benign signals of an expansile, lobulated, cystic mass on the proximal femur, intracystic hemorrhage. c AP plain radiograph of the left hip and proximal femur after 3 years of surgery showing good incorporation of the graft, consolidation of the proximal femur, preservation of the hip joint and loose proximal screws

bone tumor, which means if not treated properly, it may recur, or if left untreated, it may get larger and be called giant $\mathrm{ABC}$. Although the pathogenesis of $\mathrm{ABC}$ is still unknown, the two broad types are either primary (70\%) or secondary (30\%). Primary ABCs arise de novo. A secondary $\mathrm{ABC}$ develops in association with other neoplasms, 
most commonly GCT of the bone, osteoblastoma, chondroblastoma and fibrous dysplasia [3]. Radiographically, the diagnosis of an $\mathrm{ABC}$ shows five classic findings [9]. First, the neoplasm typically presents as an expansile lytic lesion with a soap-bubble appearance. Second, it presents an eccentric lesion outlined by a thin layer of subperiosteal new bone. Third, it presents a centric lesion. Fourth, it reveals a metaphyseal lesion that occupies a large percentage of the bone with trabeculations at the edges. Fifth, it manifests soft tissue expansion and destruction of the cortex. None of these criteria could fit any of our patients; consequently, we suggest that, if the cyst's transverse diameter on radiographic examination is equal to or more than three times the diameter of the adjacent normal bone, we can call it giant $\mathrm{ABC}$; in this case, it can be treated by resection and fibular strut graft. Most of the available surgical methods are suitable for treating metaphyseal localized lesions. However, with the use of extensive curettage and bone graft with or without adjuvant methods, there is a considerably high rate of complications $[10,11]$. However, when the extremity lesion is giant, any treatment method other than complete resection and reconstruction will have a high propensity to increased morbidity of repeated surgeries and a high possibility for pathological fracture. In giant ABCs, preservation of the bone length is important for good function of the affected limb and nearby joints. In our patients, none of the common modalities of treatment other than complete resection would have been sufficient to cause permanent cure. Non-vascularized autogenous bone grafts are biologically active grafts with relatively low donor site complications that will be replaced completely by living bone and that are capable of remodeling to fulfill the function need [6, 12-15]. Its cortical composition provides immediate stability to the surrounding joints [16]. The longterm possible complications of this procedure include fracture of the graft, non-union, failure of incorporation of the graft, and stiffness or degenerative arthrosis in the joints $[17,18]$. Non-union was observed in the humerus case and delayed union in the proximal femur case, but both patients were treated successfully by rigid fixation. None of our patients had donor site morbidity, and regeneration of the fibula at the donor site occurred within 3 months in the two children. To ensure long-term graft incorporation, the fibular cortical grafts bridged the bone defect after the resection of diaphyseal bone cyst, which should be securely anchored onto the normal bone with a supplemental form of internal fixation; this will promote union of the cortical graft to the host bone [18]. All our patients were supplemented by fixation early or late to achieve this goal.

The ability of the implanted fibular autograft to induce bone formation depends on the early periosteal connections between the autograft and the ends of the resected bone, and it spreads distally along the graft, resulting in autograft to bone union [19]. Osteogenic activity of the fibular autograft is confined to callus formation and trabecular formation within it [19]. We attributed the success of incorporation of the strut fibular graft in our cases to the rich blood supply of the recipient sites and the surrounding well-vascularized soft tissues of the ABC in the proximal femur, humerus and metatarsal.

This will enhance vascularization of the non-vascularized fibular bone graft.

We conclude that strut ipsilateral fibular autograft can be successfully used in the reconstruction of defects observed after resection of giant $\mathrm{ABC}$ with excellent clinical and radiological results at final follow-up.

Conflict of interest The authors declare that they have no conflict of interest related to the publication of this manuscript.

Open Access This article is distributed under the terms of the Creative Commons Attribution Noncommercial License which permits any noncommercial use, distribution, and reproduction in any medium, provided the original author(s) and source are credited.

\section{References}

1. Dahlin DC, McLeod RA (1982) Aneurysmal bone cyst and other nonneoplastic conditions. Skeletal Radiol 8:243-250

2. Brindley GW, Greene JF Jr, Frankel LS (2005) Case reports: malignant transformation of aneurysmal bone cysts. Clin Orthop Relat Res 438:282-287

3. Bonakdarpour A, Levy WM, Aegerter E (1978) Primary and secondary aneurysmal bone cysts: a radiological study of 75 cases. Radiology 126:75-83

4. Panoutsakopoulos G, Pandis N, Kyriazoglou I, Gustafson P, Mertels F, Mandahl N (1999) Recurrent $(16 ; 17)$ (q22; p13) in aneurysmal bone cyst. Genes Chromosome Cancer 26:265-266

5. Herens C, Thiry A, Dresse MF, Born J, Flagothier C, Vanstraelen G, Allington N, Bex V (2001) Translocation (16; 17) (q22; p13) is a recurrent anomaly of aneurysmal bone cysts. Cancer Genetics Cytogenet 127:83-84

6. Wilson PD Jr (1972) A clinical study of the biomechanical behavior of massive bone transplants used to reconstruct large bone defects. Clin Orthop 87:81-109

7. Enneking WF, Eady JL, Burchardt H (1980) Autogenous cortical bone grafts in the reconstruction of segmental skeletal defects. J Bone Joint Surg [Am] 62:1039-1058

8. Yadav SS (1990) Dual-fibular grafting for massive bone gaps in the lower extremity. J Bone Joint Surg [Am] 72:486-494

9. Campanacci M, Capanna R, Picci P (1986) Unicameral and aneurysmal bone cysts. Clin Orthop 204:25-36

10. Vergel de dios AM, Bond JR, Shives TC, Mcleod RA, Unni KK (1986) Aneurysmal bone cyst: a clinicopathologic study of 238 cases. Cancer 69:2921-2931

11. Cottalorda J, Kohler R, Chotel F, de Gauzy JS, Lefort G, Louahem D, Bourelle S, Diméglio A (2005) Recurrence of aneurysmal bone cysts in young children: a multicenter study. J Pediatr Orthop [B] 14:212-218

12. Burchardt (1983) The biology of bone graft repairs. Clin Orthop $174: 28-42$

13. George B, Abudu A, Grimer RJ, Carter SR, Tillman RM (2008) The treatment of benign lesions of the proximal femur with non- 
vascularised autologous fibular strut grafts. J Bone Joint Surg [Br] 90:648-651

14. Krieg AH F, Hefti F (2007) Reconstruction with non-vascularised fibular grafts after resection of bone tumours. J Bone Joint Surg [Br] 89:215-221

15. Lee EH, Goh JC, Helm R, Pho RW (1990) Donor site morbidity following resection of the fibula. J Bone Joint Surg $[\mathrm{Br}]$ 72:129-131

16. Finkemeier CG (2002) Bone grafting and bone graft substitutes. J Bone Joint Surg [Am] 84:454-464

17. Weiland AJ, Phillips TW, Randolph MA (1984) Bone grafts: a radiologic, histologic, and biomechanical model comparing autografts, allografts, and free vascularized bone grafts. Plast Reconstr Surg 74:368-379

18. Basarir K, Selek H, Yildiz Y, Saglik Y (2005) Nonvascularized fibular grafts in the reconstruction of bone defects in orthopedic oncology. Acta Orthop Traumatol Turc 39:300-306

19. Zwierzchowski H, Zwierzchowska D, Synder M (1989) The value of fibular autografts in block resection of bone tumours and tumour like conditions. Int Orthop 13:113-117 